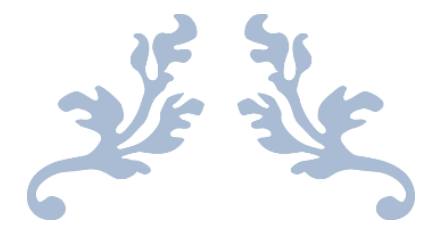

بكوث قسم التاريخ والحضارة

[Document subtitle]

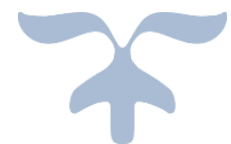


الحياة الاجتماعية للقراصنة فى الأندلس

الباحثة/ هبة كمال أحمد بخيت

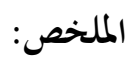

وجد للقراصنة نظام خاص في نمط المعيشة، والمسكن والمأكل والمشرب والحياة

الزوجية، وكذلك كان لا بد أن تتوفر في القرصان سمات جسدية وأخلاقية؛ تمكنه من القيام

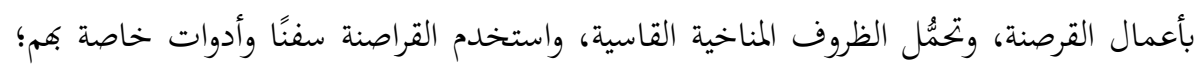

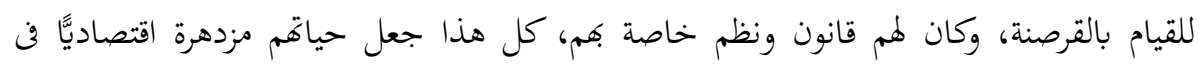
بلداغم.

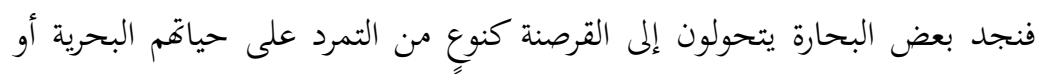

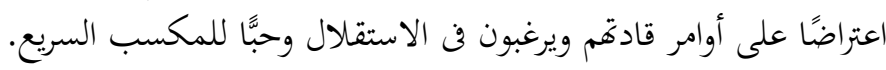

Pirates had a special order in lifestyle، housing، food، drink and married life، The pirate also had physical and moral qualities، Enable him to do piracy، And withstand harsh climatic conditions، The pirates used their own ships and tools، To do piracy، They had their own law and regulations، All this has made their lives thrive economically in their countries.

We find some sailors turning to piracy as a form of rebellion against their marine life or as an objection to the orders of their commanders and they desire independence and love for quick gain. 
يقصد بالقرصنة البحرية أها عملية سطو ثُرتكب في البحر على السفن والمسافرين، وقد

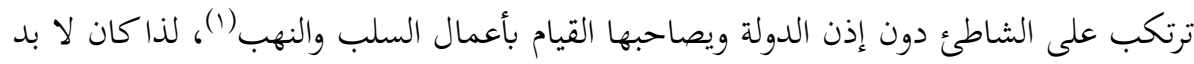

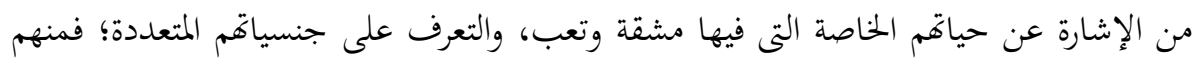

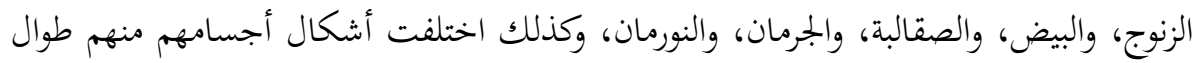

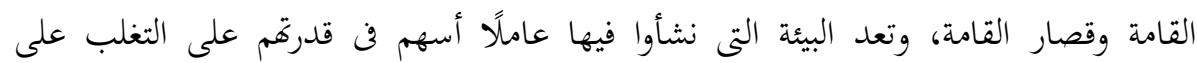

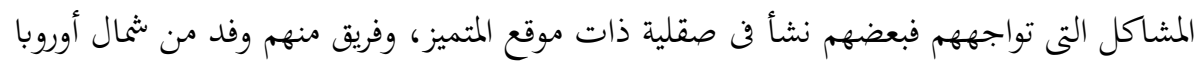

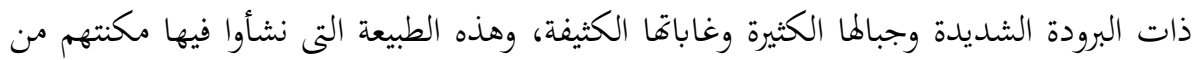
ممارسة عمليات القرصنة(r)

فنجد بعض البحارة يتحولون إلى القرصنة كنوٍٍ من التمرد على حياقم البحرية أو

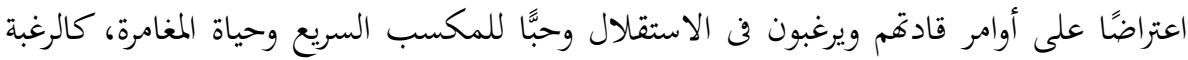

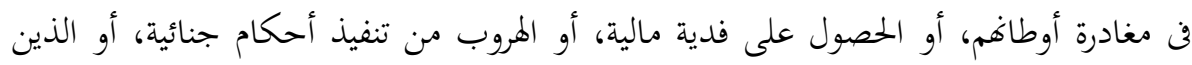

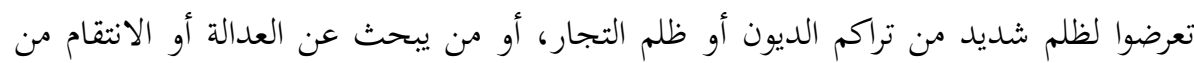

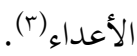

واستطاع القراصنة أن يكونوا بجتمعًا صغيرًا، مثل قراصنة الفايكنج الذين أقاموا

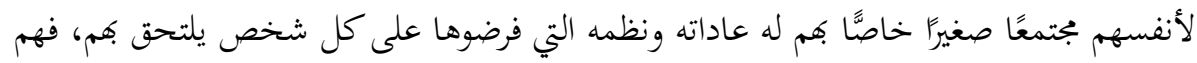

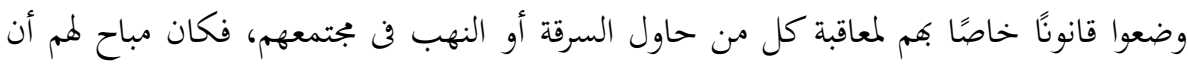

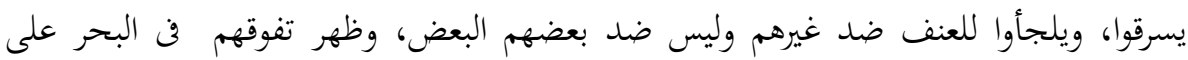

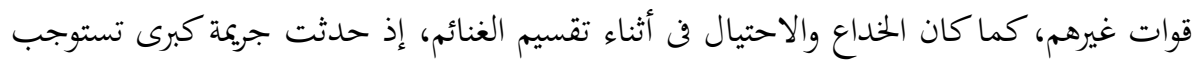

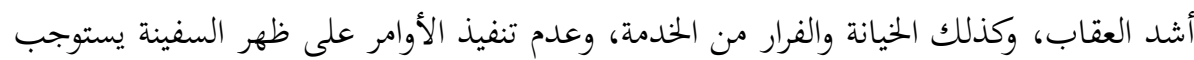
عقوبة الموت ضده؛ مما دفعهم لمغادرة وطنهم وتوجيه إغارات تركت وراءها الكثير من الدمار

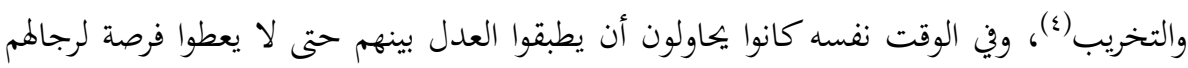

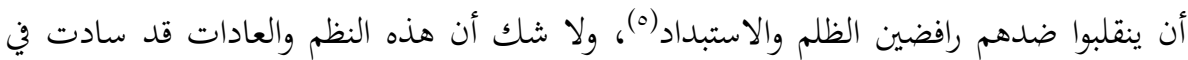

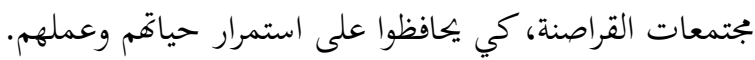


طبقات الجمتمع عند القراصنة:

ولا شك أن النظام الاقتصادى في أوروبا حينذاك، والمتمثل في النظام الإقطاعى، كان دافعًا لكثير من المغامرين إلى الهروب منه والعمل في القرصنة، وبالنسبة للهيكل التركيبى لمجتمع القراصنة(7) نجده يتألف من ثلاث طبقات هى: طبقة النبلاء الذين يقومون بالمغامرات في البحر والابحاه لعمليات الغزو والقرصنة. والطبقة الثانية الرجال الأحرار الذين يختصون بأعمال غير قتالية وأعمال الصيد والزراعة وغيرها من شئون الجزيرة. وأما الطبقة الثالثة فهى طبقة العبيد، وهم أسرى الحروب والإغارات الحربية، مما جعل هناك فوارق بين طبقات المجتمع، ليفضل زعماء كثيرون الهجرة

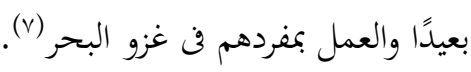

\section{مساكن القراصنة: - 20 - 20}

تمثلت معيشتهم بأها كانت حياهم غير مستقرة يتنقلون من مكان لآخر، فهم يعيشون في منازل متفرقة ما بين القرى والغابات والمستنقعات، إذ يلجئون إلى الأماكن الخالية لتكون مأوى لهم للاختباء بها، سواء كانت جزرًا أو بالقرب من الشواطئ، مثل جزيرة صقلية وسواحل ميورقة ويابسة وسردنيا، والتى جمعت العديد من القراصنة في العديد من الجزر التى كانت

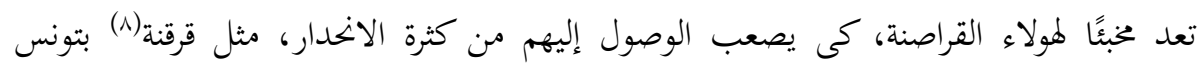
وغيرها. وكان القراصنة يبيعون ما يكصلون عليه من عمليات القرصنة في صقلية وبجانة(9)، فيعرضون المسروقات والأسرى بهما.(1).

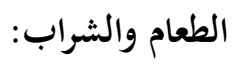

وفيما يتعلق بجانب التغذية الخاص بالقرصنة كان هذا الأمر مبنيًا فن الأساس على ما يقتنصونه من السفن من طعام وشراب؛ لذا فإغم كانوا يعملون على ملء قواركمم الخفيفة السريعة

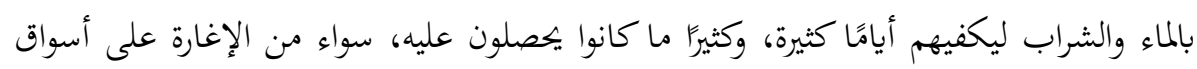

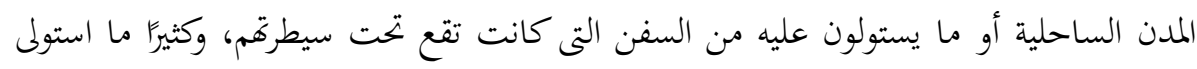

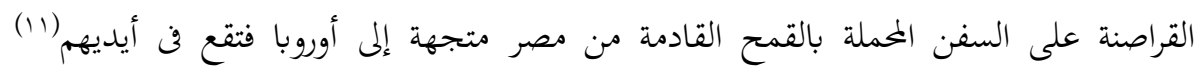
وكذلك كانوا يستولون على مراكب القمح والتوابل العائدة من بلنسية(rا)، بالإضافة إلى ما كانوا 
يسرقونه من محاصيل الزراعية وغيرها، وكذلك يقومون بشراء الطعام والشراب من الأموال التى

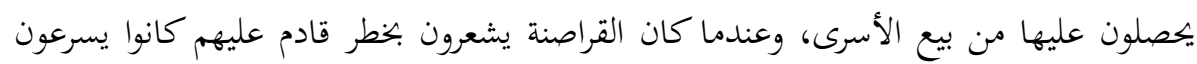

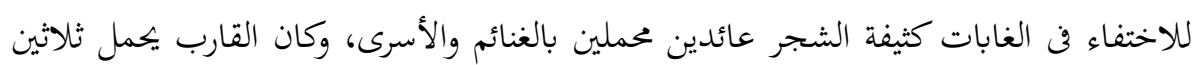
شخصًا (ri).

وبالرغم من سرقتهم واحتياجهم للمؤن الغذائية والشعور بالنقص والحرمان(\&)، نجد

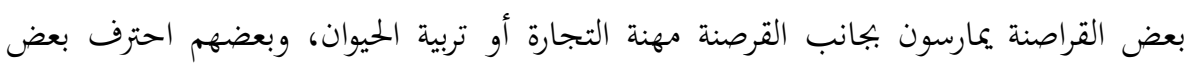

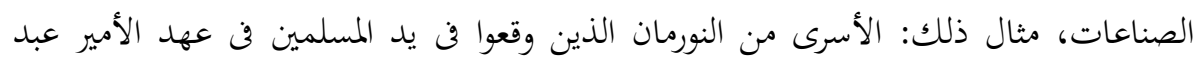

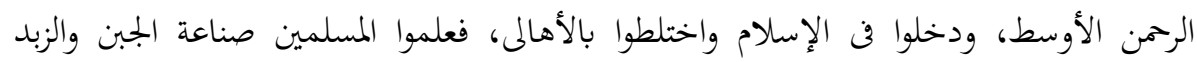
وغيرهما من منتجات الألبان(1)، وقد برع القراصنة فن صيد الأسماك والحيتان وأسماك القرش، فئإن إنسان الغزو فن نظرهم أفضل من العمل فن مشقة الحياة، كما عرف عنهم شرب الخمر لدرجة أفم كانوا

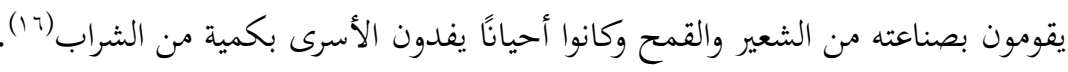

\section{الحياة الزوجية:}

اختلفت الحياة الزوجية عند القراصنة من فئة إلى أخرى حيث نجدها ذات طابعٍ

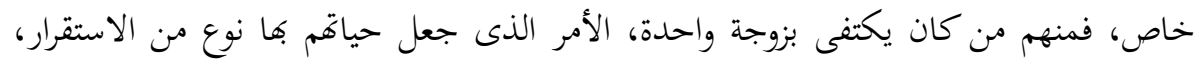

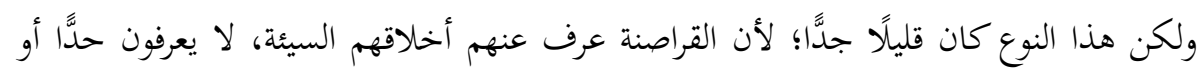

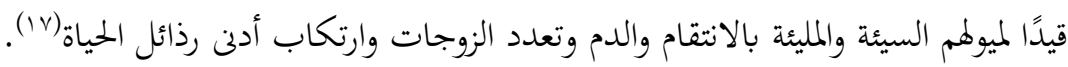

ومن عادات الزواج أن يقدم العريس- وخاصة عند القراصنة النورمان- لأهل العروس

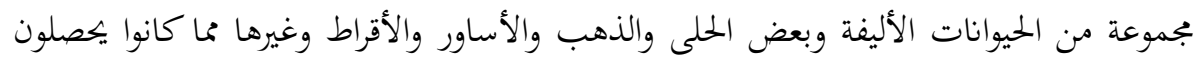

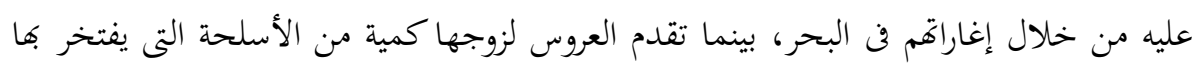

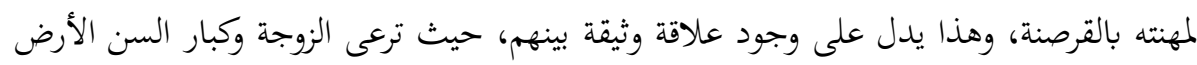

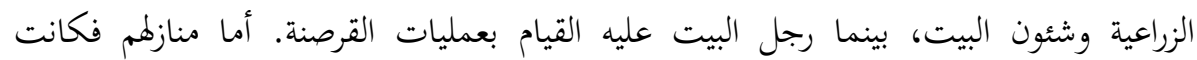

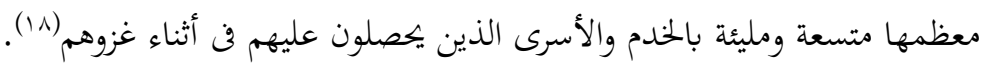


وفيما يتعلق بملابسهم فلم نجد فيما أطلعت عليه من مصادر أن القراصنة- على

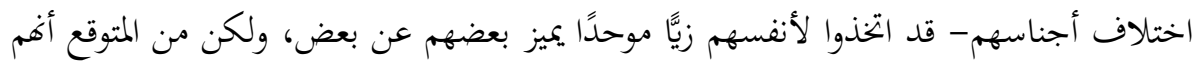

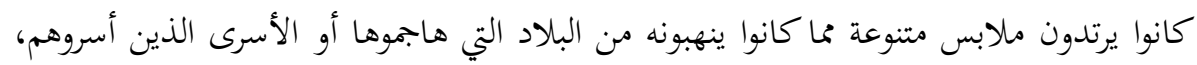

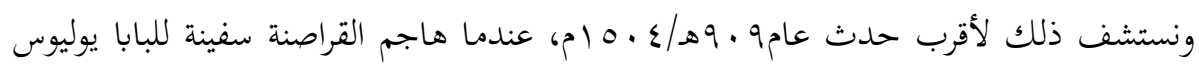

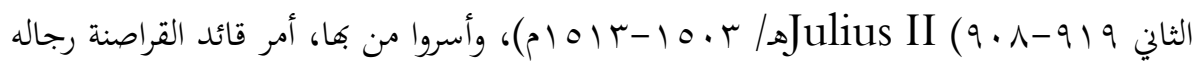

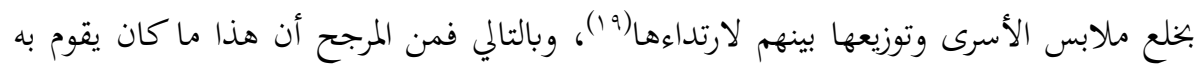
أغلب القراصنة في العصور الوسطى.

وفى بجتمعهم نجد أن ملابسهم كانت من جلود الحيوانات، وهى عبارة عن عباءة

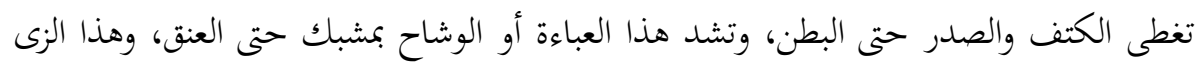

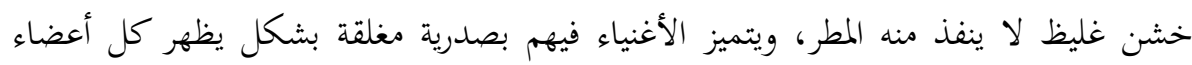

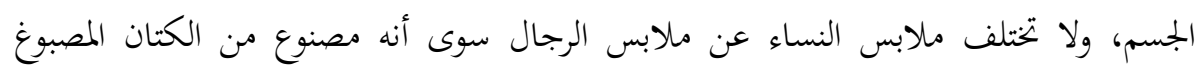
بالأحمر، ومن عادات النساء ترك الذراعين وأجزاء من الصدر عارية(r.).

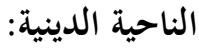

انتشرت الديانة الوثنية بين القراصنة، وتعددت المعبودات وأهمها النار والتى اشتهروا

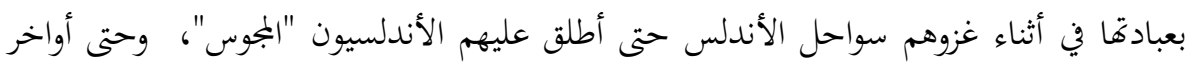

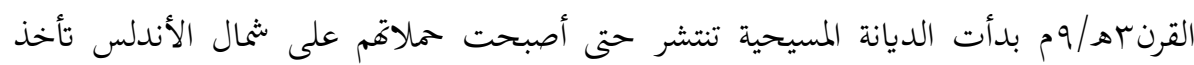

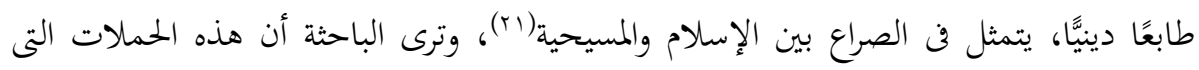

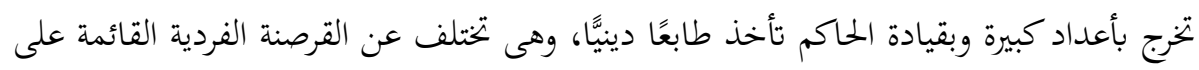
بضعة أشخاص فهم قراصنة لا يفرق معهم الديانة أكثر من قيامهم بأعمال السلب والنهب.

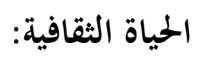

نجد في الحياة الثقافية أن القرصان لا يشغله أمر التعليم والثقافة، فهو لا يتعلم سوى

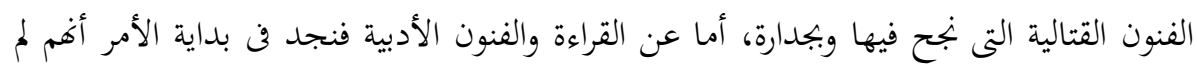

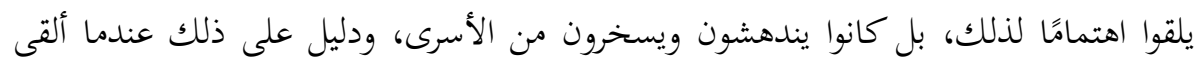


يوليوس قيصر الذى وقع أسيرًا عند القراصنة شعرًا، أخذوا يسخرون منه(Yr)، ومع التوسع

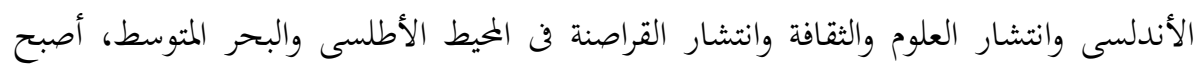

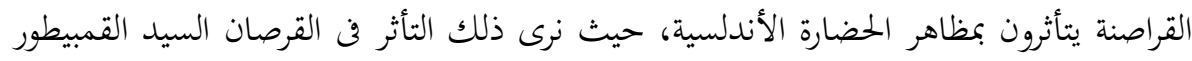

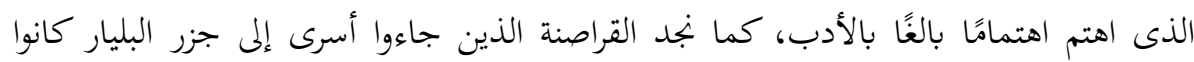

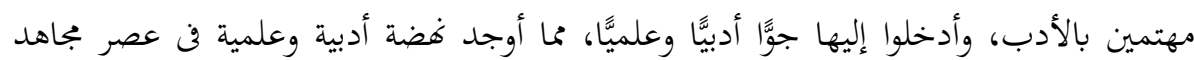
العامرى، حيث وفد إليها العلماء والأدباء(rr).

ومن المتوقع أن يكون ربابنة سفن القراصنة، على اختلاف جنسياتم كانوا في الأصل

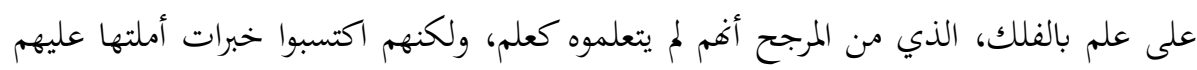

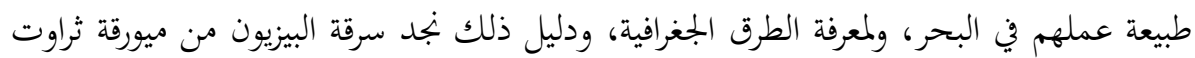

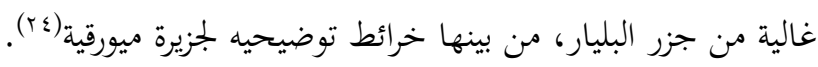

\section{صفات القرصان:}

تتميز صفات القرصان الجسمانية والخُلقية والتي فرضتها عليهم طبيعة عملهم المحفوف

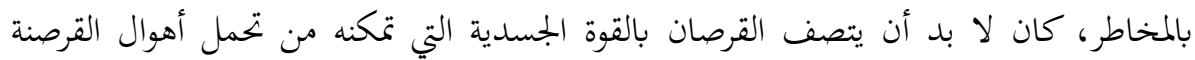

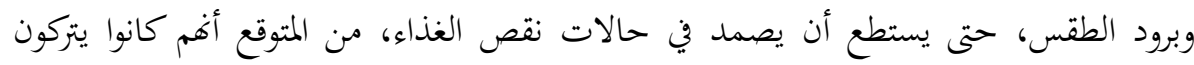

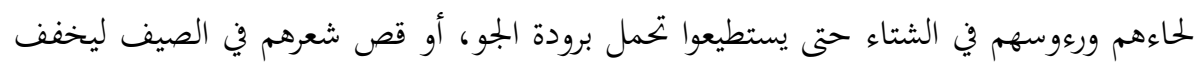
عليهم حرارة الجو (ro).

إذ اتصف القراصنة بصفات حُلقية تتسم بالشجاعة والبسالة والجرأة التي بتعلهم

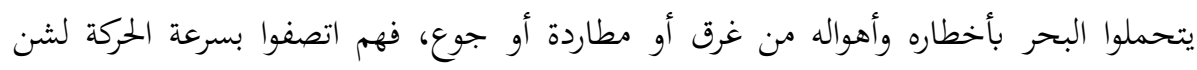

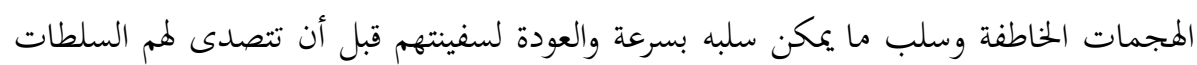

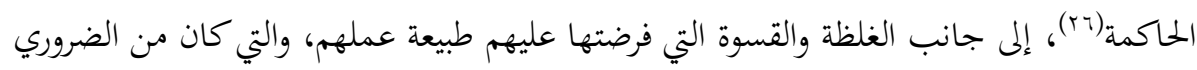

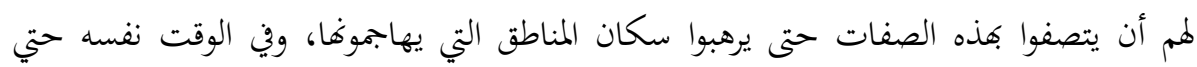

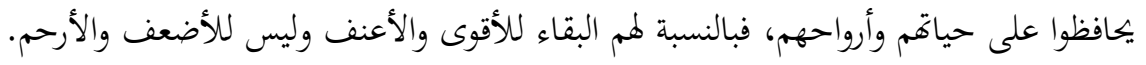


كما تميزوا بحبهم الشديد للقتال، فقد حرصوا على تعليم أطفالهم فنون القتال والسباحة وركوب البحر، كما حرصوا على توفير أساطيل لأطفالهم للإغارة في المناطق القريبة منهم، كنوع من التدريب والخوض فن مغامرات البحر، ويتم اختيار الأفضل من الرجال ممن لديهم القدرة على استخدام عنصر المفاجأة للقيام بالمهام الكبرى في البحر(rv).

ونظرًا لقوة بنياهم نجد أن الحكام والملوك كانوا يستعينون بهم فن أوقات الحروب، في حروبكم ضد دولة أخرى؛ لذا نجد القرصنة أحيانًا كانت مرخصة ومدعمة من قبل الدولة مقابل جزء من الأرباح، وأحيانًا أخرى كانت غير مدعمة، مما جعل القرصان يهتم بتجنيد القراصنة وإخضاعهم لعمليات التدريب والتعليم وإعطاء مكافئة مالية ضخمة لمن ينجح فن التدريب، وكان هذا التدريب يشبه تدريب الملاحين التجاريين، فلا بد أن يكونوا ماهرين وخبراء في فنون القتال والشئون البحرية؛ لكى يقوموا بعمليات الغزو البحرى(^)، ومن أمثلة القراصنة الذين استعان بهم بنو هود لدولتهم: رجل اشتهر بالقوة والشجاعة "الغشتى"، وقد جمع تحت يده جماعة من الرجال والسباع، واشتهروا بالسرقة والنهب في شرق الأندلس(ج).

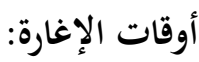

وبالنسبة لأوقات الإغارة نجد أن القراصنة يتركون أوطاغم خاصًة في فصلي الصيف والربيع ويبدأون فن شن الإغارات على المدن، ثم يعودون في فصل الخريف لأوطافم ليقضوا الشتاء به، وكانت تقوم عمليات التدريب والتعليم عند الجزر والمضايق في الأوقات التى تتوقف فيه الملاحة في فصل الشتاء فن البرد القارس، وعندما كانت هذه الرحلة البحرية السنوية طويلة ومرهقة ومحفوفة بالمخاطر، كان هذا يدفعهم- في كثير من الأحيان- إلى الاستيلاء على بعض المواقع الحصينة القريبة من المحيط الأطلسي لتكون معقلاً وملجًُا لمم في فصلي الشتاء والخريف، حيث تتجنب القراصنة الإبحار فن فصل الشتاء لظروف الجو (r.).

لذلك نجد النساء من الضحايا اللاتي يسكنن بالجزر أو بالقرب من السواحل كن يختبئن فن فصل الصيف داخل حصن بعيد عن البحر ومعهن امتعتهن وكانوا الرجال يعملون في التجارة في المرسى أو يغيبون للعمل بالتجارة في الأسطول؛ وذلك خوفا من ظهور القراصنة

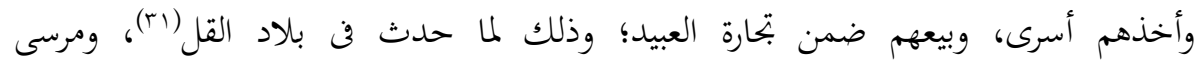


الدجاج(rr)، وهذا ما جعل معظم الحكام والخلفاء الأندلسيين يهتمون بناء الأربطة والحصون والمنارات لحماية سواحل الأندلس (rr).

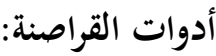

لقد ظهرت أساليب وأدوات خاصة للقراصنة لممارسة عمليات القرصنة، فمن الأساليب والحيل التى لجأ إليه القراصنة في اصطياد السفن استخدام عنصر المفاجأة، حيث يتحرك

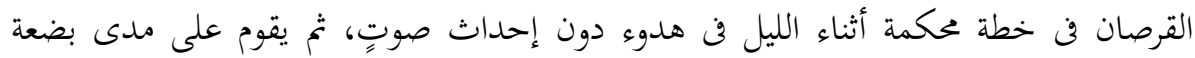
ساعات بأعمال التجسس، بعدها بدقائق يقتربون من سفن الضحايا، وعند طلوعهم السلالم

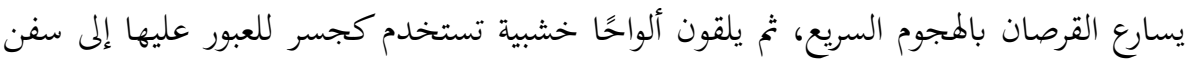

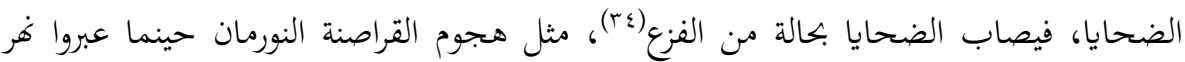

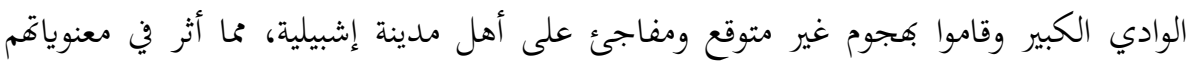
القتالية في البداية؛ ويرجع ذلك لسرعة وصول قوات النورمان للمدينة(ro).

وكان قارب القراصنة يحمل ثلاثين رجلاً، وكان هجوم القراصنة على سفن أعدائهم

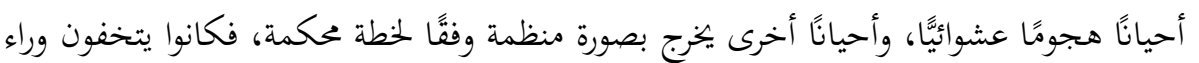

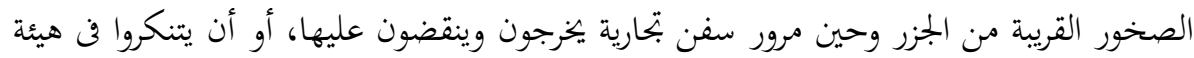

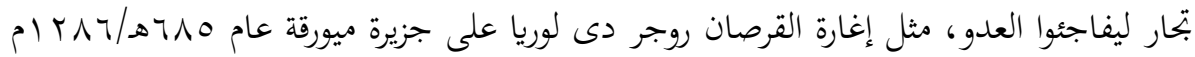

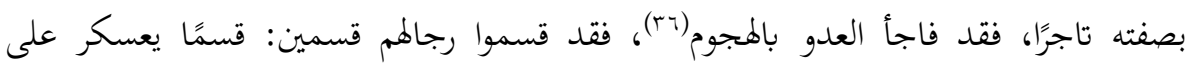

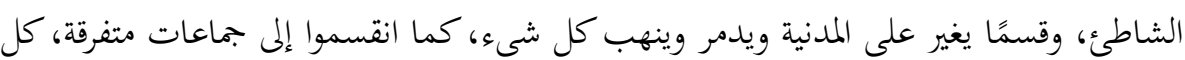
مجموعة تعمل لحساها الخاص، وكانت هذه الجماعة تتجنب السواحل المحصنة وقماجم السواحل غير المحصنة "المكشوفة"(rv).

وإذا كانت الحمولة التى تقع في يديهم ثقيلة فيأخذون على قدر السفينة؛ حتى لا

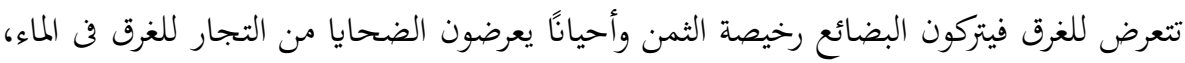
كما يتعرض الضحايا إلى الضرب والإهانة، وخاصة النساء والأمراء لطلب الفدية، كما كان

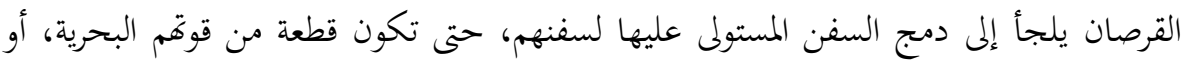


يتركوفا في أحد الشواطئ، أو يشعلون النار بها، وبعد الرجوع يقتسمون الغنائم حسب العرف

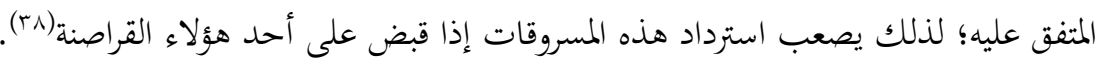

ومن أكثر الأسلحة التى استخدمها القراصنة في هجومهم على سواحل الأندلس:

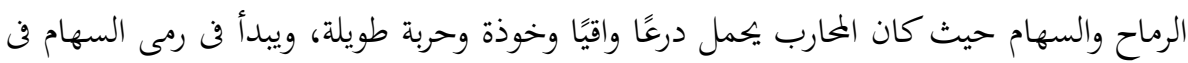

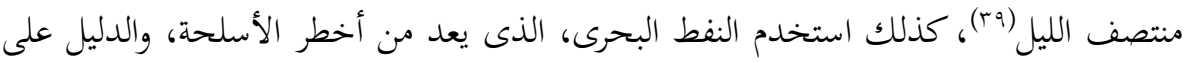
استخدام القراصنة النفط البحرى استخدام القراصنة النورمان له في هجومهم على سواحل

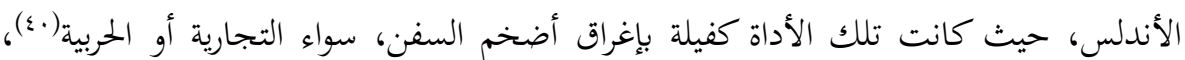

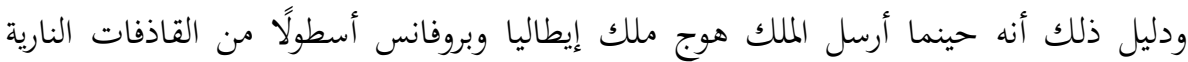

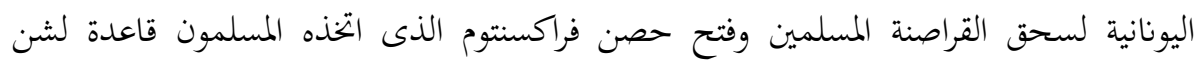

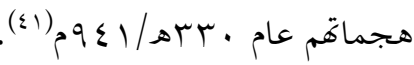

ومن الأدوات أيضًا القسئٌ والحراب، والأتراس وقبضات السيوف التى كانت مزينة

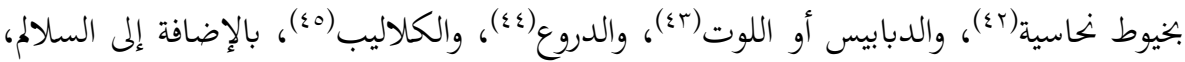

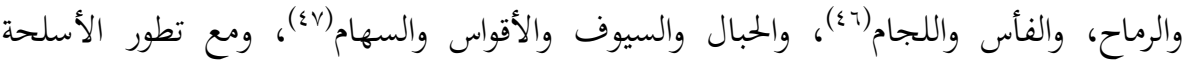

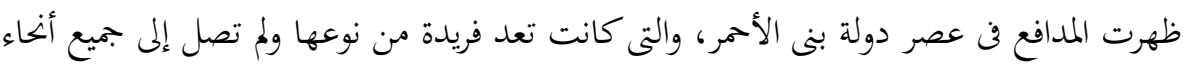

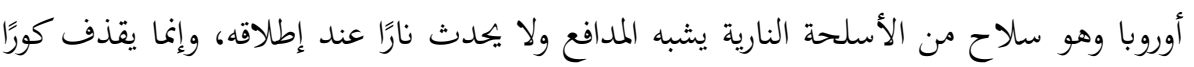
نارية معدنية أو حجرية قابلة للانفجار والاشتعال وتتكون هذه الكور النارية من النفط والنشادر والكبريت والملح البارود وحصى الحديد؛ وبذلك يسهل السفينة إغراق أضخم السفن سواء لهنه

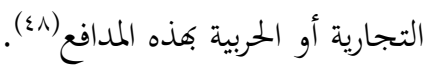

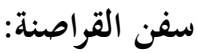

تتميز سفن القراصنة بأهما طويلة ذات أشرع سوداء، ضيقة ذات مقدمة، تبحر باستخدام المجاديف، وكان لكل نوع من السفن زى خاص، فكانت السفن تدهن باللون الأسود،

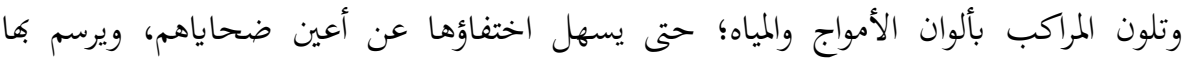

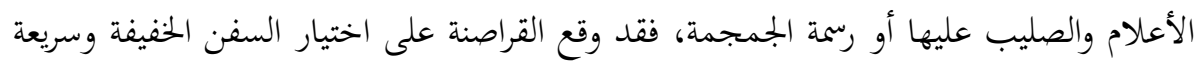

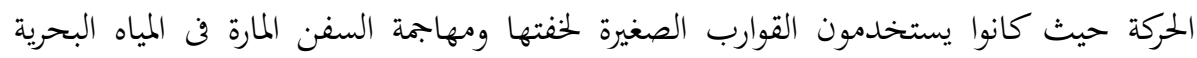


فكان القرصان غالبًا، يكتفى بأول مركب يكصل عليه، فالكل يعمل كفريق واحد لتنفيذ تلك المهمة (59).

ومن أمثلة السفن التى استخدمها القراصنة: الغراب، والطرائد، والقراقير، والمسطحات

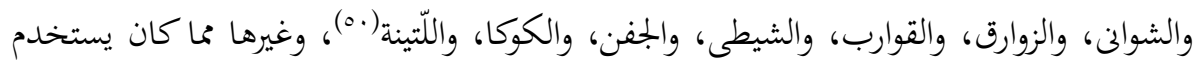

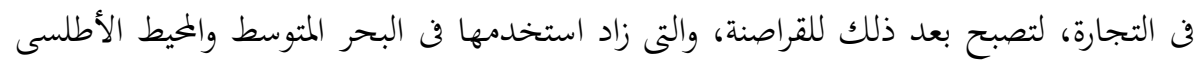

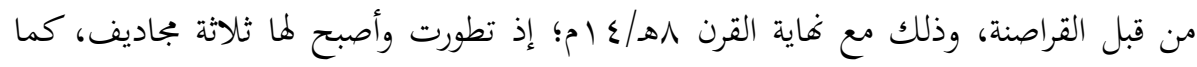

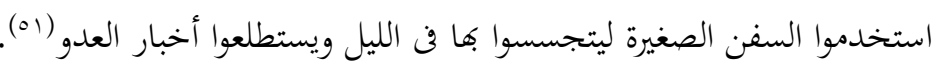

نستشف من هذا البحث أن للقراصنة نظام خاص في نمط معيشتهم، من مسكن ومأكل ومشرب وحياة الزوجية، وأن للقرصان سمات جسدية وأخلاقية مكنته من القيام بأعمال

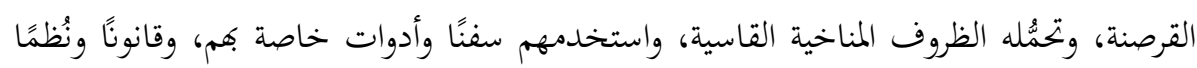
خاصة بكم، كل هذا جعل حياتم مزدهرة اقتصاديَّا في بلدافم. 


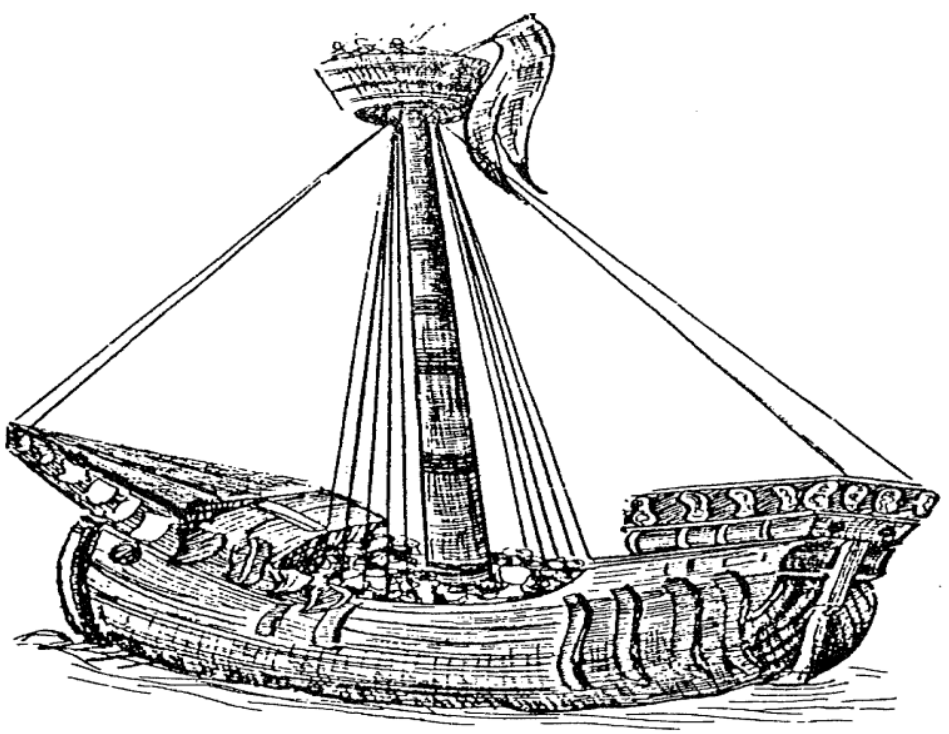

سفن حراريق

$$
\text { نقلا عن: وفيق بركات: فن الحرب البحرية، ص ا }
$$

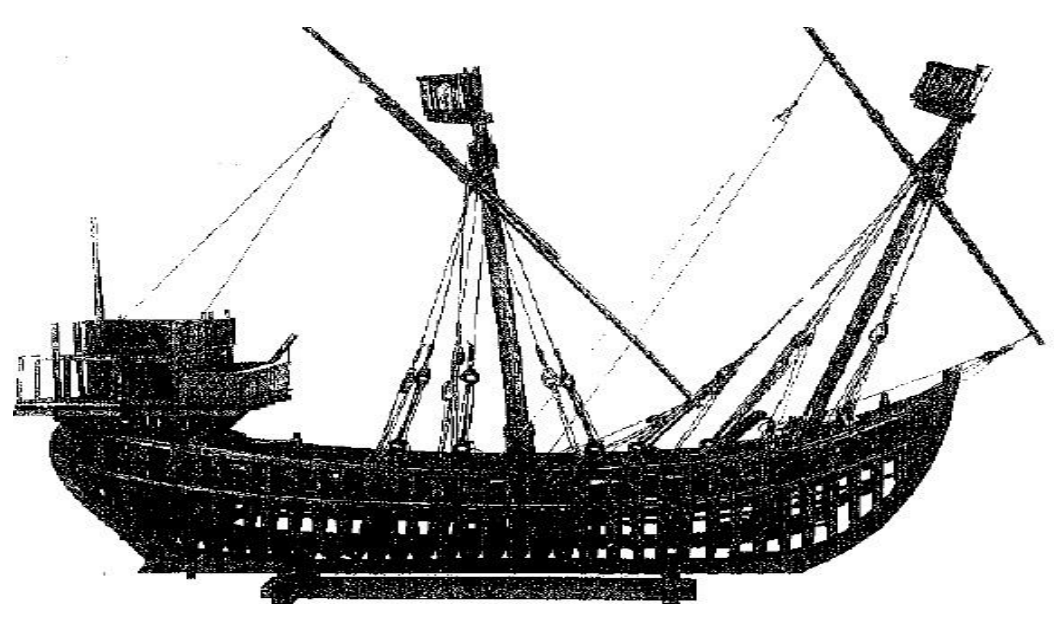

سفينة الكوك

نقلا عن: ابن خلدون: المتوسط في القرن الرابع عشر، صץ | $\varepsilon \ldots$ 
(') روبرت هايوود، روبرتا سبيفاك: القرصنة البحرية، ترجمة: أحمد ياسين، طا، مركز الإمارات للدراسات

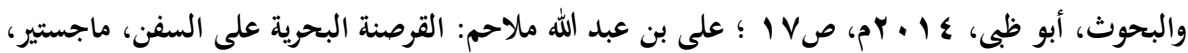

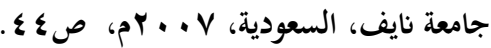

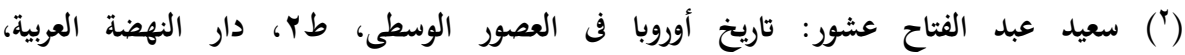

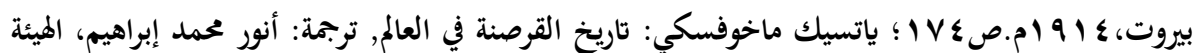

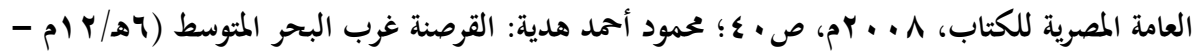

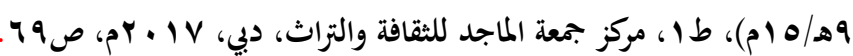

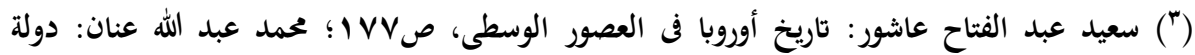

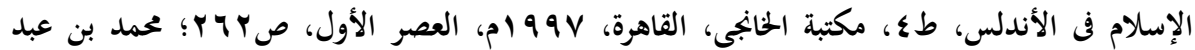

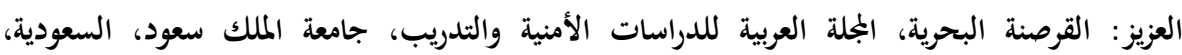

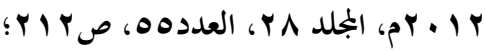
Peter Sawyer: The Oxford Illustrated History of the Vikings, oxford university press, New York, । १९v, p.r; Katherine Holman: Dictionary of the Vikings, The scarecrow press, oxford, r..r, p.v.

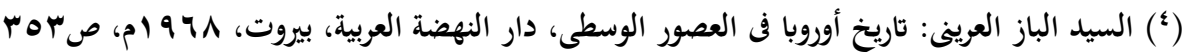
؛ ياتسيك ماخوفسكي: تاريخ القرصنة في العالم, ص V \؛ انتصار محمد: التحديات الداخلية والخارجية التى لى

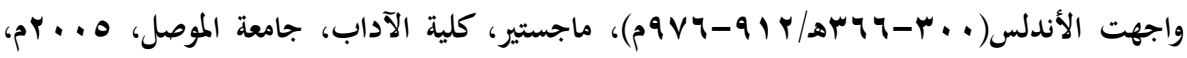
ص • • 1؛ نيفين ظافر:الأوضاع الدينية والسياسية والاقتصادية والاجتماعية فى الغرب الأوروبى، ماجستير،

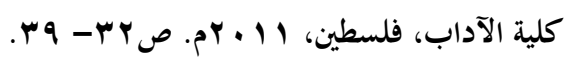

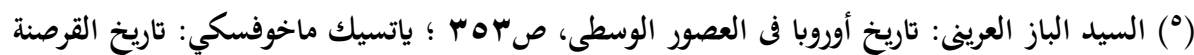

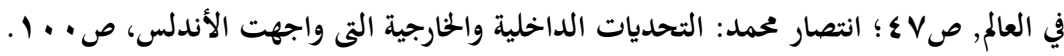

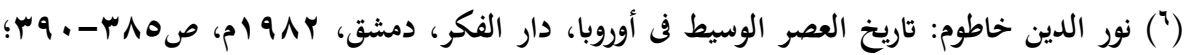

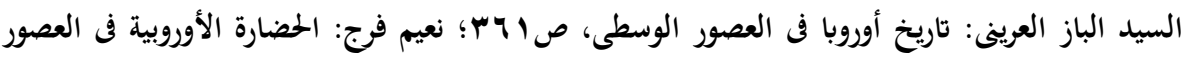

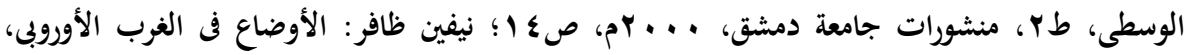

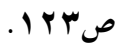
(vه ه.و.ويفز: أوروبا فى العصور الوسطى، ترجمة: عبد الحميد حمدى ، طا، دار المعارف، الاسكندرية، هـ (9 ام، ص^ه؛ وليم لانجر: موسوعة تاريخ العالم، ترجمة:عبد المنعم أبو بكر، مكتبة النهضة المصرية، 


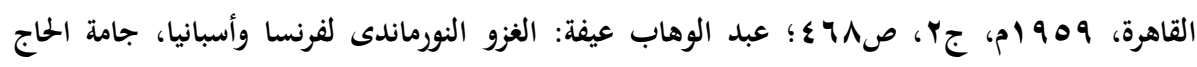

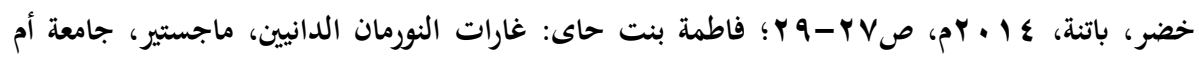

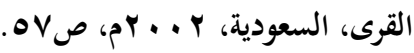
(^) قرقنة: هى جزيرة عامرة بالسكان يملأُها الكروم والأعناب ، تقع بين قصر زياد وصفاقس، طولها ستة

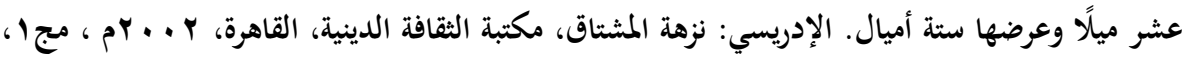

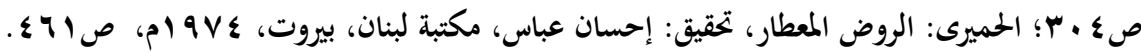

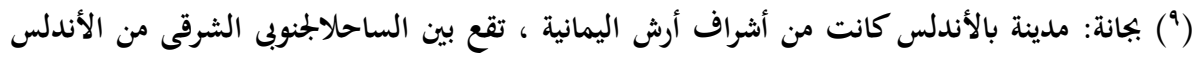

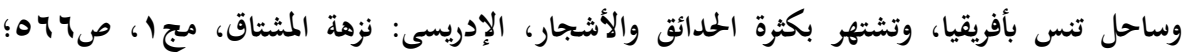

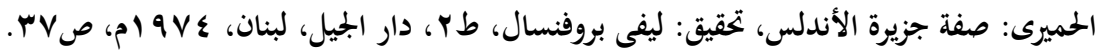

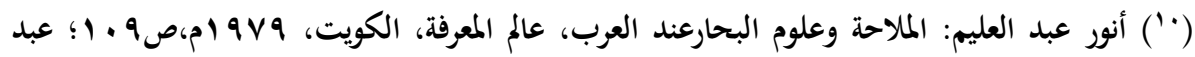

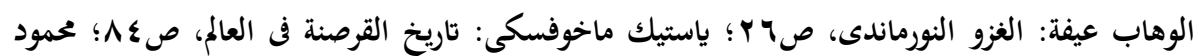

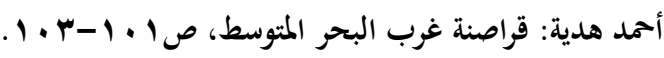

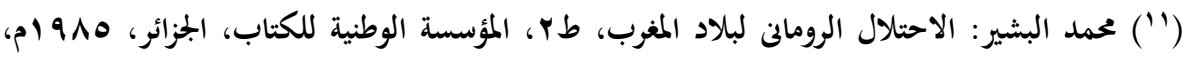

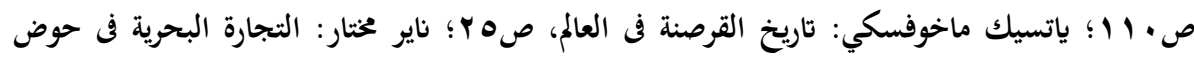

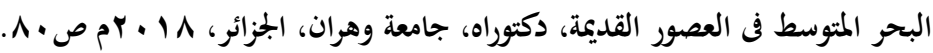

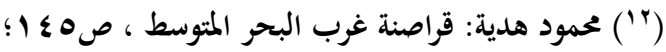

Maria Teresa: Corsarios vascos en el Mediterráneo medieval, Sociedad Española de Estudios Medievales, †. . ч,p.१^.

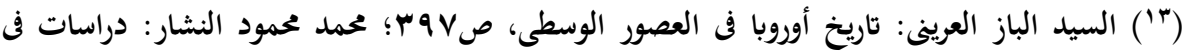

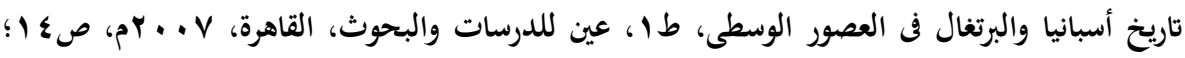

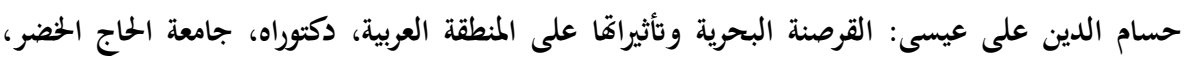

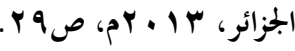

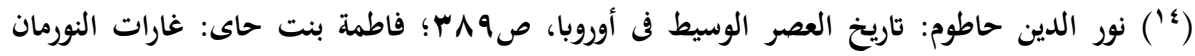

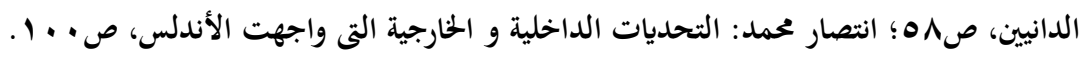
(10) ابن عذارى: بيان المغُرب في تاريخ الأندلس والمغرب، تحقيق: ج.س.كولان، ليفى برفنسال، دار

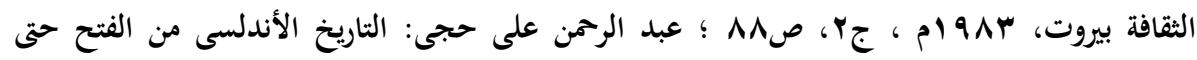

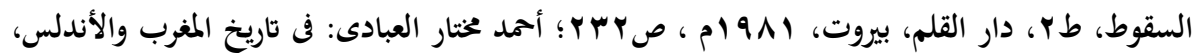

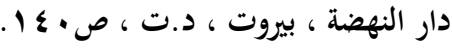




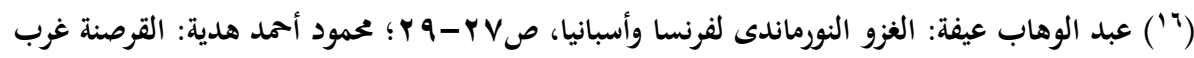

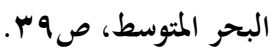

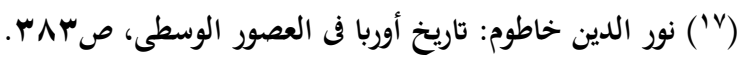

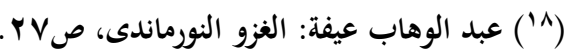

('9) Alfred S. Bradford ,Flying the Black Flag: A Brief History of Piracy: A Brief History of Piracy, Praeger, London, r..v, p. rr.

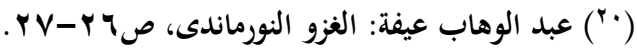

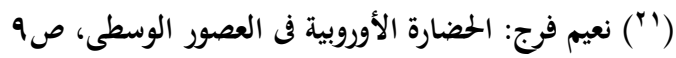

Tracey Ann Schofield: Vikings, print United states of America, r...r, p.r $;$; Angus A. Somerville, R. Andrew McDonald: The Vikings and Their Age, university of Toronto press, r. 1 r, p. 7 .

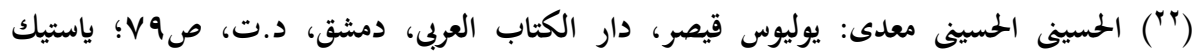

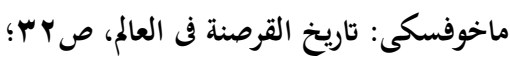
Luciano Canfora, Julius Caesar: The Life and Times of the People's Dictator, university of California press, Los Angeles, r..v, p. १; Philip

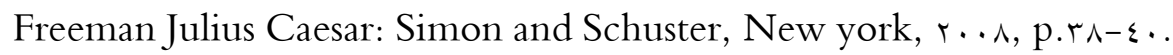

(بT) ابن بسام : الذخيرة في محاسن أهل الجزيرة، تحقيق: إحسان عباس، دار الثقافة، بيروت،

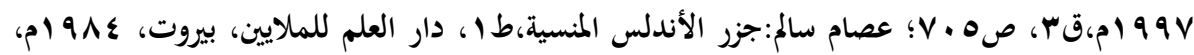

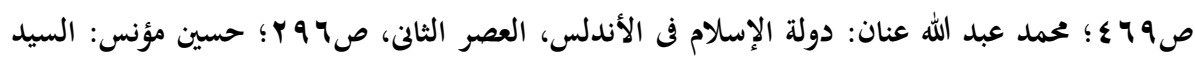

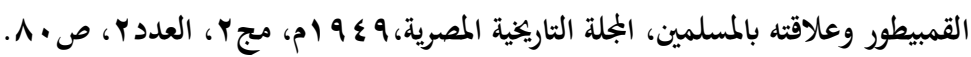

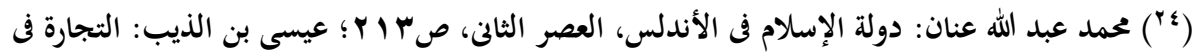

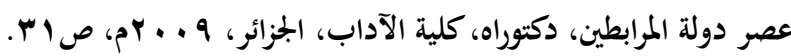

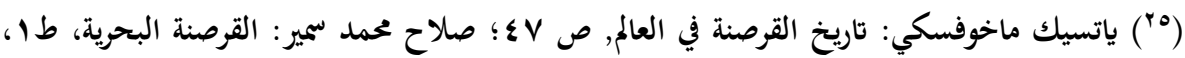

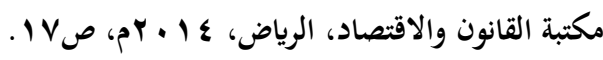

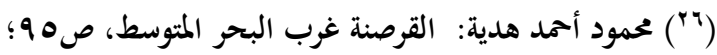

Thomas K. Heebøll, Ports: Piracy and Maritime War, Brill, Boston, r.ır, p.rA.

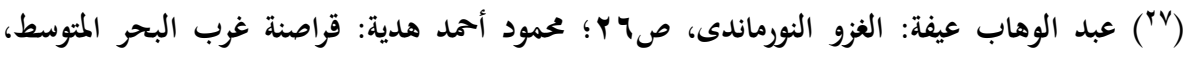
ص104. 


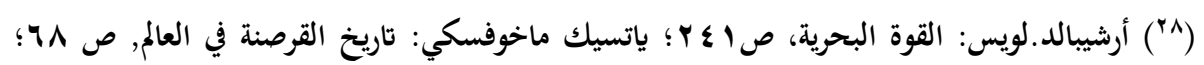

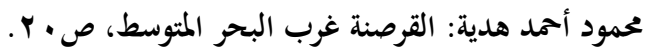

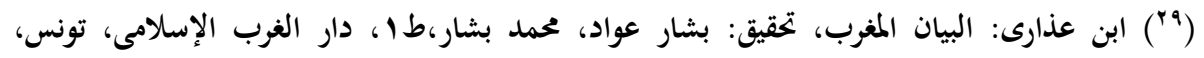

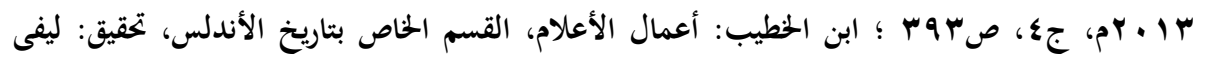

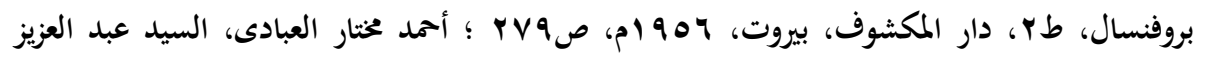

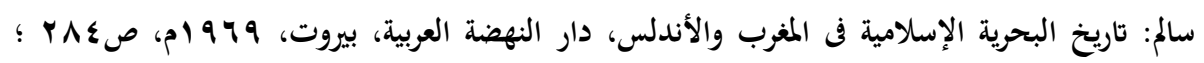

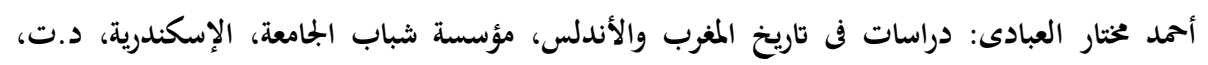
ص.

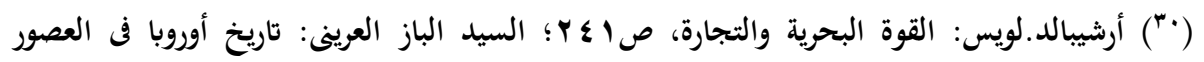

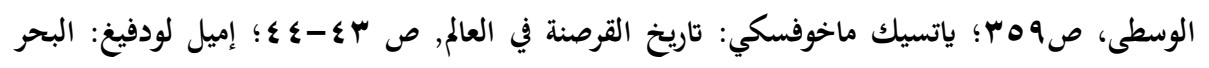

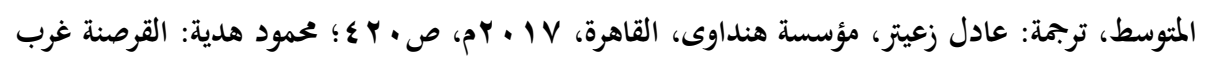

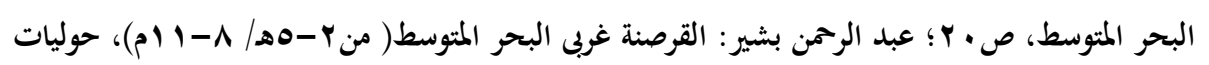

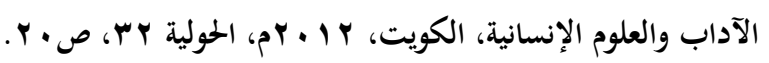
('آم' القل: مدينة بالساحل تقع شرق بجانة، وهو مكان مشهور بساحل قسنطينة، وبينهما أربعون ميلًا،

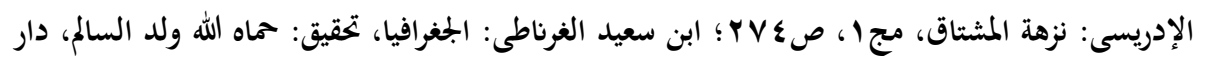

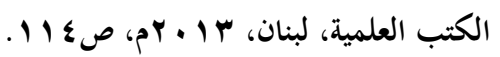

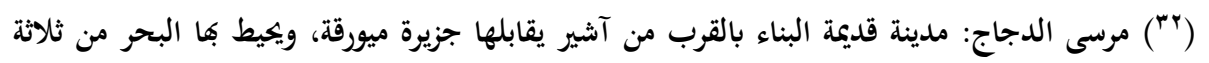

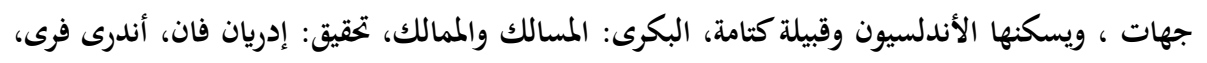

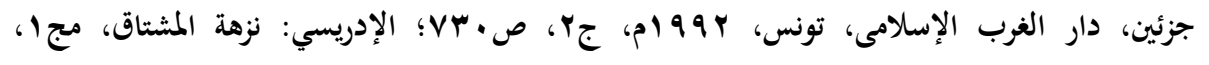

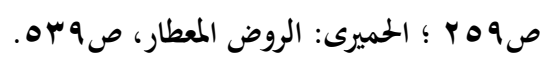

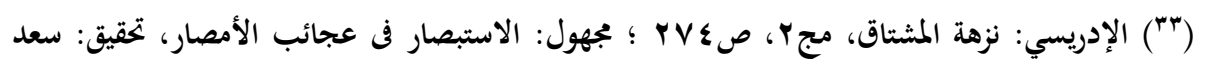

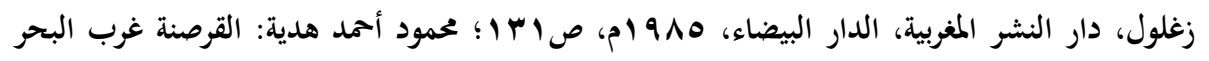

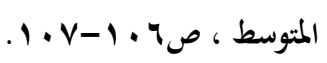

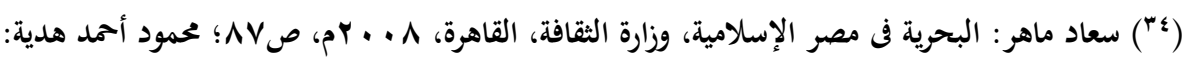

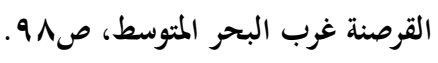

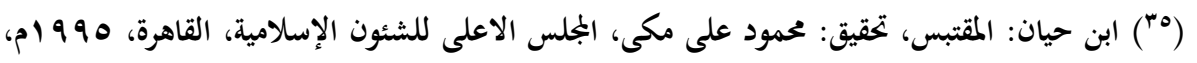

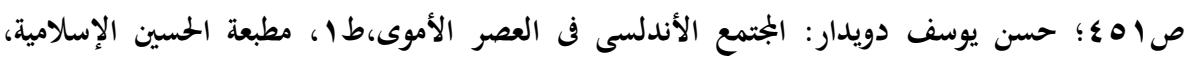

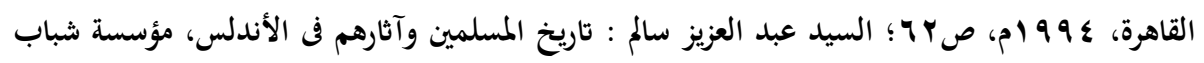

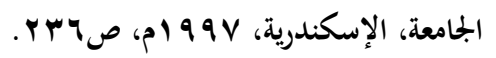




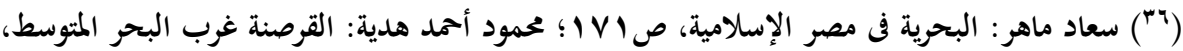

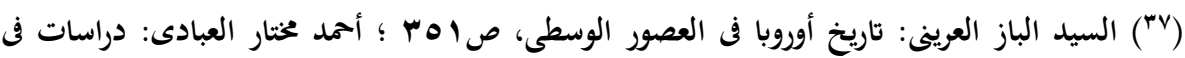

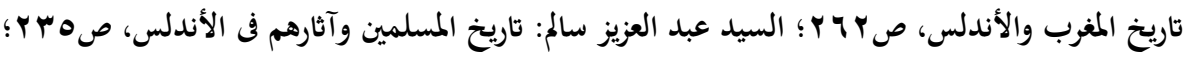

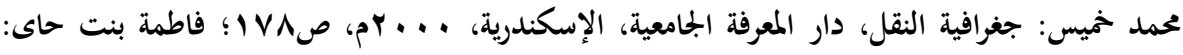

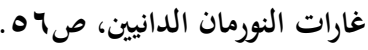

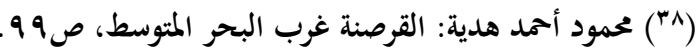

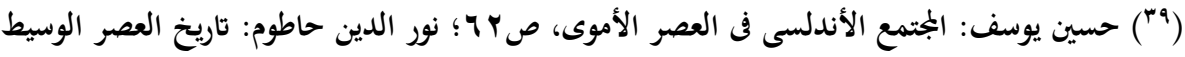

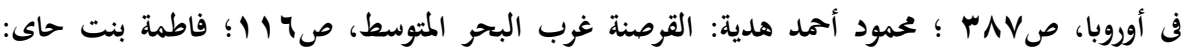

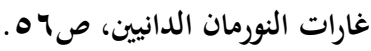

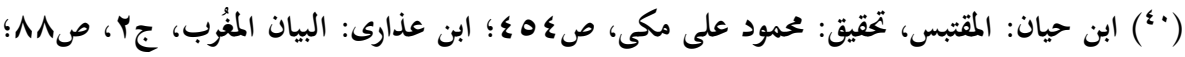

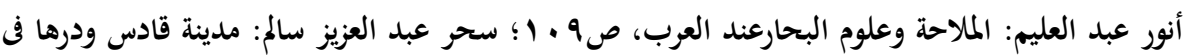

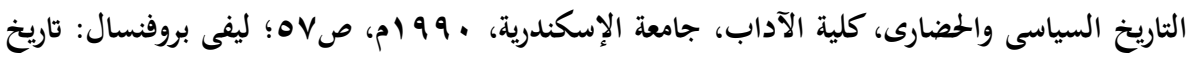

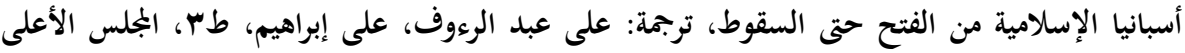

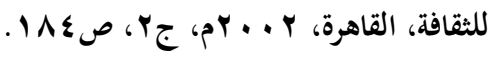

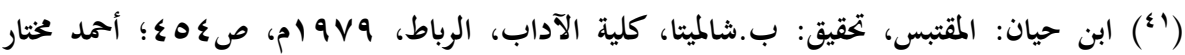

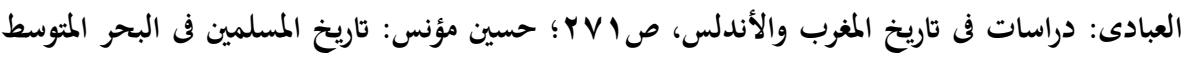

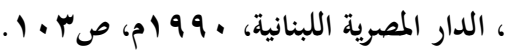

(ז^) المراكشى: المعجب فى تلخيص أخبار المغرب، تحقيق: محمد زينهم، دار الفرجالى للنشر والتوزيع،

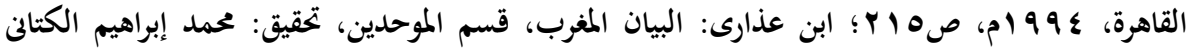

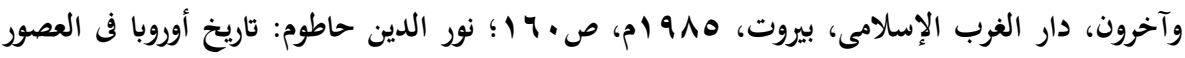

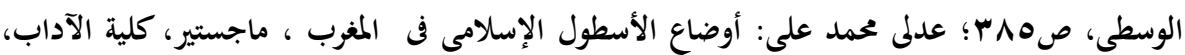

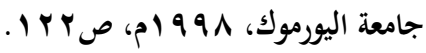

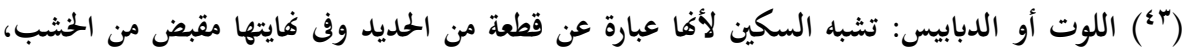

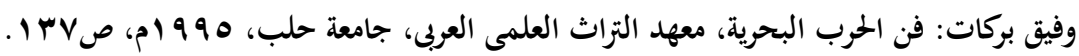

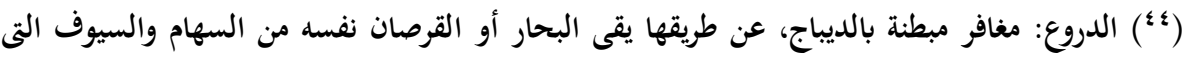

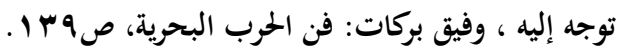


(0 ؛ الكلاليب: خطاطيف حديدية استخدمها البحارة للرمى على مراكب العدو، وهى ذات رأس مسنونة، استخدمت لجذب السفن، فتضرب بفأس صغير فولاذ يقطعه. وفيق بركات: فن البحرية الإسلامية،

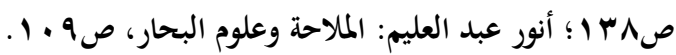

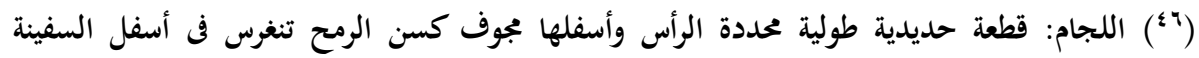

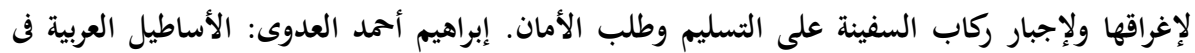

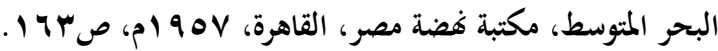

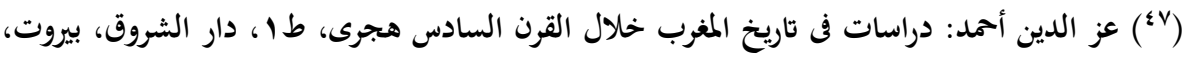

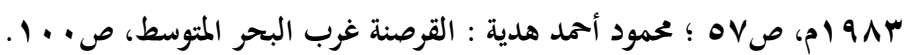
(^^) ابن الخطيب: الإحاطة فى أخبار غرناطة، تحقيق: محمد عبد الله عنان، طץ، مكتبة الخانجى، القاهرة،

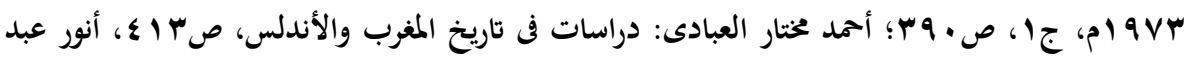
العليم: الملاحة وعلوم البحار، صبه ؛ محمد عبد الله عنان: دولة الإسلام فى الأندلس، العصر الرابع،

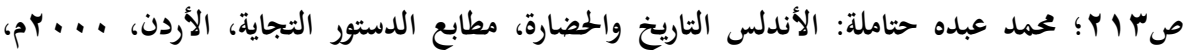

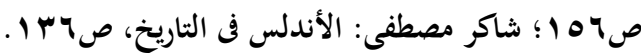
(9) العذرى: نصوص عن الأندلس، تحقيق: عبد العزيز الأهوانى، منشورات معهد الدراسات الإسلامية،

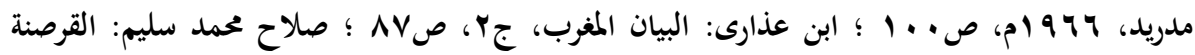

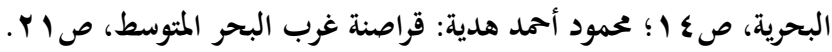

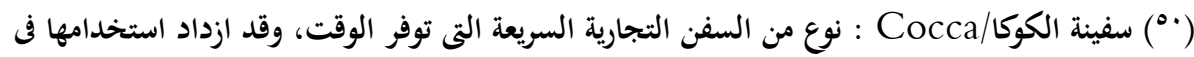

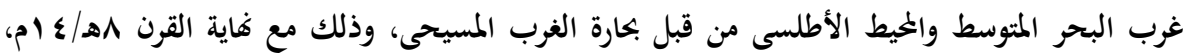
وقاموا بتطويرها وأصبح لها ثلاث مجاديف. أما سفن اللّتينة/Latina فهى سفن على شكل مثلى مثلث، ولها القدرة على أن تسير عكس اتجاه الرياح بخلاف القرقور الذى يسير فى اتجاه الرياح، وقد قام الأوروبيون ببناء نفس النوع من السفن لتكون أكبر حجمًا، ولها القدرة على عبور الخيط الأطلسى والقيام بالرحلات الاسكتشافية العظيمة. ابن خلدون: البحرالمتوسط فى القرن الرابع عشر قيام وسقوط إمبراطوريات، تحقيق:

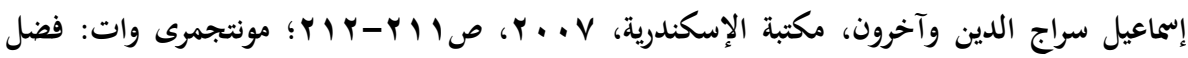

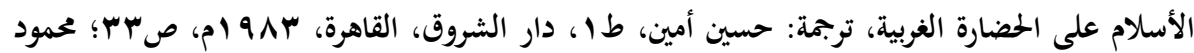

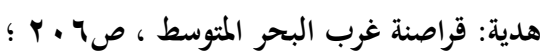
Jerzy Gawronski ,André van Holk ,Joost Schokkenbroek :Ships and maritime landscapes, Barkhuis publishing, Amstrdam, r. I v, p.r^. 


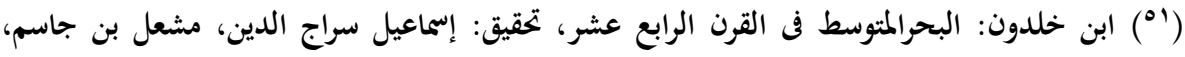

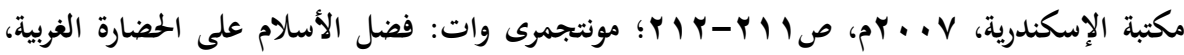

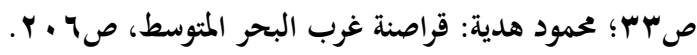


قائمة المصادر والمراجع

\section{أولَا: المصادر العربية:}

الإدرسيى: أبو عبيد الله محمد بن عبد الله بن إدريس الحمودى (ت. ـ7 7 هـ/7 1 1 م)

- نزهة المشتاق في اختراق الأفاق، مجلدين، مكتبة الثقافة الدينية، القاهرة، ب . . F ـ

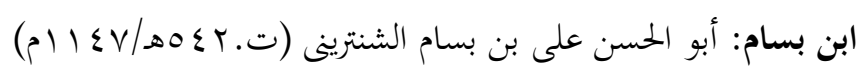

- الذخيرة فن محاسن أهل الجزيرة، تحقيق : إحسان عباس، مجr، ق ب، دارالثقافة،

$$
\text { بيروت، } 199 \mathrm{~V}
$$

$$
\text { البكرى : أبو عبيد الله عبد الله بن عبد العزيز البكرى (ت. Vیعهـ/ع م ام) }
$$

- المسالك والممالك، تحقيق: إدريان فان، أندرى فرى، جزئين، دار الغرب الإسلامى،

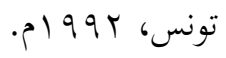

$$
\text { الحميرى: أبو عبد الله محمد بن عبد المنعم (ت. . }
$$

- الروض المعطار فن أخبار الأقطار، تحقيق: إحسان عباس، مكتبة لبنان، بيروت،

- صفة جزيرة الأندلس، تحقيق: ليفى بروفنسال، طץ، دار الجيل، لبنان، عVل ام.

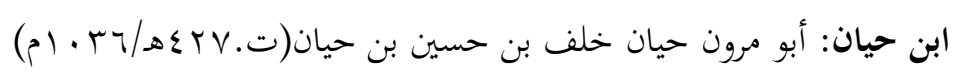

- المقتبس من انباء أهل الاندلس، تحقيق: محمود على مكى، السفر الثانى، المجلس

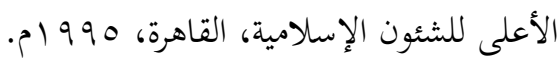

- المقتبس من أنباء أهل الاندلس، تحقيق: ب.شالميتا، كلية الآداب، الرباط، 9V9 وم. 


\section{ابن الخطيب : محمد بن عبدالله بن سعيد بن الخطيب (ت.}

- الإحاطة في أخبار غرناطة تحقيق: محمد عبدالله عنان، طץ، ج؟، مكتبة الخانجى

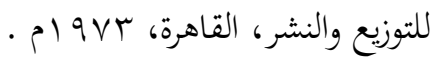
- أعمال الأعلام، القسم الخاص بتاريخ الأندلس، تحقيق: ليفى بروفنسال، طب، دار المكشوف، بيروت، 907 (م.

$$
\text { ابن خلدون : أبا زكريا يهيى بن خلدون (ت.ت. }
$$

- البحرالمتوسط فن القرن الرابع عشر قيام وسقوط إمبراطوريات، تحقيق: إسماعيل سراج

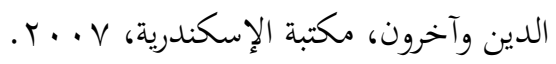

\section{ابن سعيد الغرناطى}

- الجغرافيا، تحقيق: حماه الله ولد السالم، دار الكتب العلمية، لبنان، با ـ بم.

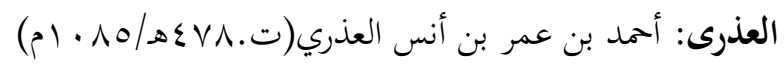

- نصوص عن الأندلس، مقتبس من ترصيع الأخبار وتنويع الاثار، تحقيق: عبد العزيز

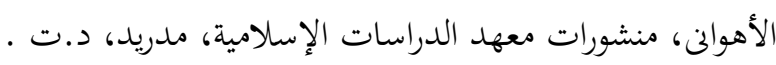

$$
\text { ابن عذارى: أبو العباس أحمد بن محمد (ت.تقريبا T ا هـ/ T T I م) }
$$

- البيان المغُُب فن تاريخ الأندلس والمغرب، تحقيق: ج.س.كولان، ليفى برفنسال،

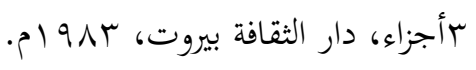

- البيان المغرب، تحقيق: بشار عواد، محمد بشار، طل، جـ، دار الغرب الإسلامى،

$$
\text { تونس، rا ب ب م. }
$$


- البيان المغرب، تحقيق: محمد إبراهيم الكتانى، محمد بن تاويت، عبد القادر زمامة، جه،

$$
\text { دار الغرب الإسلامى، بيروت، } 910 \text { ام. }
$$

$$
\text { المراكشى : عبد الواحد على التميمى المراكشى (ت. V乏 7هـ/q ؟ ام) }
$$

- المعجب فن تلخيص أخبار المغرب، تحقيق: محمد زينهم، دار الفرجان للنشر والتوزيع،

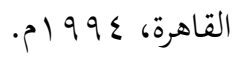

\section{مؤلف مجهول:}

- الاستبصار في عجائب الأمصار، تحقيق: سعد زغلول، دار النشر المغربية، الدار

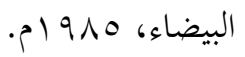

\section{ثانياً: المراجع العربية والمعربة:}

- إبراهيم أحمد العدوى: الأساطيل العبية في البحر المتوسط، مكتبة هضة مصر،

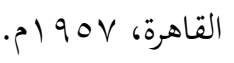

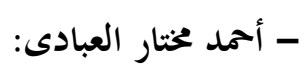

* ف تاريخ المغرب والأندلس، دار النهضة، بيروت، د.ت.

* دراسات في تاريخ المغرب والأندلس، مؤسسة شباب الجامعة، الإسكندرية، د.ت.

- أمد مختار العبادى، السيد عبد العزيز سالم: تاريخ البحرية الإسلامية فن المغرب

$$
\text { والأندلس، دار النهضة العربية، بيروت، } 999 \text { أم. }
$$

- أرشيبالد.لويس: القوة البحرية والتجارة، ترجمة: أحمد محمد عيسى، مكتبة النهضة

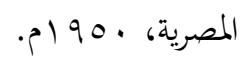


- إميل لودفيغ: البحر المتوسط، ترجمة: عادل زعيتر، مؤسسة هنداوى، القاهرة، $.5 r \cdot 1 \mathrm{R}$

- أنور عبد العليم: الملاحة وعلوم البحارعند العرب، عالم المعرفة، الكويت، 9 ال م. - حسن يوسف دويدار: المجتمع الأندلسى فن العصر الأموى، طا، مطبعة الحسين الإسلامية، القاهرة، 999 ام.

- الحسينى الحسينى معدى: يوليوس قيصر، دار الكتاب العربى، دمشق، د.ت.

- حسين مؤنس: تاريخ المسلمين فن البحر المتوسط، الدار المصرية اللبنانية، ـ99 م. - روبرت هايوود، روبرتا سبيفاك: القرصنة البحرية، ترجمة: أحمد ياسين، طا، مركز

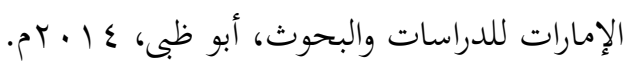

- سحر عبد العزيز سالم: مدينة قادس ودرها في التاريخ السياسى والحضارى، كلية

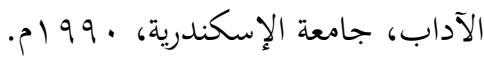
- سعاد ماهر : البحرية في مصر الإسلامية، وزارة الثقافة، القاهرة، م · ب بم. - سعيد عبد الفتاح عشور: تاريخ أوروبا في العصور الوسطى، ط ب، دار النهضة العربية، بيروت، ع| (9) مام. - السيد الباز العرينى: تاريخ أوروبا في العصور الوسطى، دار النهضة العربية، بيروت، .01971

- السيد عبد العزيز سالم : تاريخ المسلمين وآثارهم في الأندلس، مؤسسة شباب

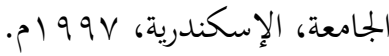


- صلاح حممد سمير: القرصنة البحرية، طا، مكتبة القانون والاقتصاد، الرياض،

PY. Is

- عبد الرمن على حجى: التاريخ الأندلسى من الفتح حتى السقوط، طب، دار القلم،

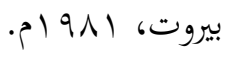

- عبد الوهاب عيفة: الغزو النورماندى لفرنسا وأسبانيا، جامة الحاج خضر، باتنة، . Pr. I

- عدلى محمد على: أوضاع الأسطول الإسلامى في المغرب خلال القرنين7،06،

$$
\text { ماجستير، كلية الآداب، جامعة اليورموك، } 991 \text { ام. }
$$

- عز الدين أحمد: دراسات ف تاريخ المغرب خلال القرن السادس هجرى، ط ا، دار

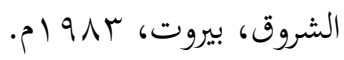

- عصام سالم: جزر الأندلس المنسية، طلا، دار العلم للملايين، بيروت، ع 91 ام.

- ليفى بروفنسال: تاريخ أسبانيا الإسلامية من الفتح حتى السقوط، ترجمة: على عبد

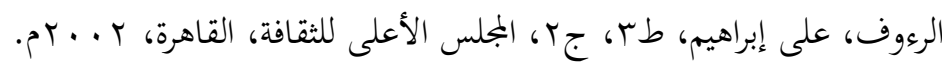
- محمد البشير: الاحتلال الرومانى لبلاد المغرب، طب، المؤسسة الوطنية للكتاب،

ـ محمد خميس: جغرافية النقل، دار المعرفة الجامعية، الإسكندرية، . . . بام. - محمد عبد الله عنان: دولة الإسلام في الأندلس، طع، ع أقسام، مكتبة الخانجى،

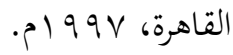
- محمد عبده حتاملة: الأندلس التاريخ والحضارة، مطابع الدستور التجاية، الأردن، 
- محمد محمود النشار: دراسات فى تاريخ أسبانيا والبرتغال في العصور الوسطى، طاه

$$
\text { عين للدرسات والبحوث، القاهرة، V. . ץ بم. }
$$

- محمود أحمد هدية: القرصنة غرب البحر المتوسط (7ه/ץ ام -9هـ/ه ام)، طا، مركز جمعة الماجد للثقافة والتراث، دبي، ل ا ـ بم.

- مونتجمرى وات: فضل الأسلام على الحضارة الغربية، ترجمة: حسين أمين، طا، دار

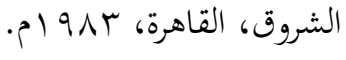

- نعيم فرج: الحضارة الأوروبية في العصور الوسطى، طب، منشورات جامعة دمشق،

$$
\text { . }
$$

- نور الدين خاطوم: تاريخ العصر الوسيط فن أوروبا، دار الفكر، دمشق، بم9 ام. - هـ.و.ويفز: أوروبا فن العصور الوسطى، ترجمة: عبد الحميد حمدى، طا، دار المعارف،

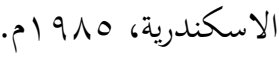

- وفيق بركات: فن الحرب البحرية، معهد التراث العلمى العرب، جامعة حلب،

- وليم لانجر: موسوعة تاريخ العالم، ترجمة:عبد المنعم أبو بكر، ج؟، مكتبة النهضة

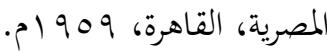

- ياتسيك ماخوفسكي: تاريخ القرصنة في العالم، ترجمة: أنور محمد إبراهيم، الميئة العامة

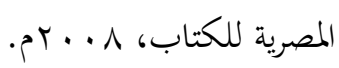




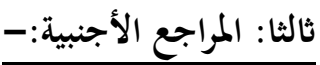

- Alfred S. Bradford، Flying the Black Flag: A Brief History of Piracy: A Brief History of Piracy، Praeger، London، $r . . v$.

- Angus A. Somerville، R. Andrew McDonald: The Vikings and Their Age، university of Toronto press، $r .1 r$.

- Jerzy Gawronski، André van Holk، Joost Schokkenbroek: Ships and maritime landscapes، Barkhuis publishing، Amstrdam، r. I v.

- Katherine Holman: Dictionary of the Vikings، The scarecrow press، oxford، r...r.

Luciano Canfora، Julius Caesar: The Life and Times of the People's Dictator، university of California press، Los Angeles، r... .

Maria Teresa: Corsarios vascos en el Mediterráneo medieval، Sociedad Española de Estudios Medievales، r. ..

- Peter Sawyer: The Oxford Illustrated History of the Vikings، Oxford University press، New York، $199 \mathrm{~V}$.

- Philip Freeman Julius Caesar: Simon and Schuster، New york، r... 
- Thomas K. Heebøll، Ports: Piracy and Maritime War، Brill، Boston، r. Ir.

- Tracey Ann Schofield: Vikings، print United States of America، r... r.

رابعا: الرسايل الجامعية والدوريات:

- انتصار محمد: التحديات الداخلية والخارجية التى واجهت الأندلس(..ب-

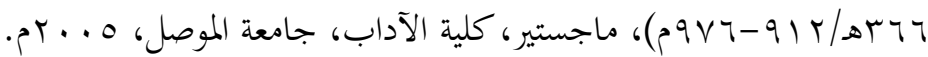

- حسام الدين على عيسى: القرصنة البحرية وتأثيراما على المنطقة العربية، دكتوراه،

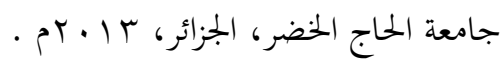

- حسين مؤنس: السيد القمبيطور وعلاقته بالمسلمين، المجلة التاريخية المصرية، مج广،

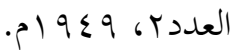

- عبد الرحمن بشير: القرصنة غربى البحر المتوسط ( منץ-هه/ ^-1 ام)، حوليات

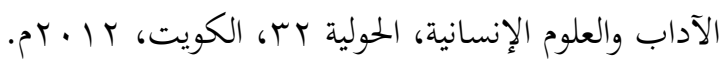

- على بن عبد الله ملاحم: القرصنة البحرية على السفن، ماجستير، جامعة نايف،

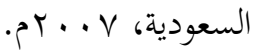

- عيسى بن الذيب: التجارة في عصر دولة المرابطين، دكتوراه، كلية الآداب، الجزائر، . $r+\cdots$ - فاطمة بنت حاى: غارات النورمان الدانيين، ماجستير، جامعة أم القرى، السعودية، 
- محمد بن عبد العزيز: القرصنة البحرية، المجلة العربية للدراسات الأمنية والتدريب، المجلد

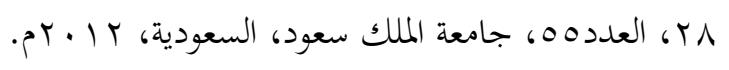

- ناير مختار: التجارة البحرية في حوض البحر المتوسط في العصور القديمة، دكتوراه، جامعة وهران، الجزائر، 11 • ب بر. - نيفين ظافر: الأوضاع الدينية والسياسية والاقتصادية والاجتماعية في الغرب الأوروبى، ماجستير، كلية الآداب، فلسطين، 1 إ. بم. 